\title{
Reordering of Depolymerized Silicates as Adsorbents for Large Nitrogen Compounds
}

\author{
Norma A. Sánchez-Flores, ${ }^{\circledR *, a}$ Juan Navarrete-Bolaños, ${ }^{b}$ Patricia Pérez-Romo, ${ }^{b}$ \\ Graciela Pacheco-Malagón, ${ }^{a}$ Georgina Laredo ${ }^{\circledR b}$ and José J. Fripiat ${ }^{\dagger}$, \\ ${ }^{a}$ Instituto de Ciencias Aplicadas y Tecnología, Universidad Nacional Autónoma de México, \\ Circuito Exterior s/n, Ciudad Universitaria, CP 04510, Mexico City, Mexico \\ ${ }^{b}$ Instituto Mexicano del Petróleo, Eje Central Lázaro Cárdenas No. 152, \\ Col. San Bartolo Atepehuacan, CP 07730, Mexico City, Mexico
}

\begin{abstract}
The adsorption capacities of two synthesized zeolites (crystalline ZSM-5 and semi-crystalline faujasite Y) for a mixture of indole, quinoline and carbazole were studied. The different samples obtained show different crystalline degree, mesoporosity and $\mathrm{Si} / \mathrm{Al}$ ratios. The synthesis procedure is based on the simultaneous depolymerization of a mixture of high surface area silica, such as rice hull ashes (RHA), and a crystalline zeolite, such as clinoptilolite or faujasite. The depolymerization step is followed by a partial reorganization induced by a structure-directing agent. A model mixture of nitrogenous compounds was prepared, then it was mixed with the zeolite samples and the amount adsorbed of nitrogenous compounds was determined by gas chromatography. Analysis of the adsorbed molecules reveals selectivity in favor of quinoline, followed by indole and then carbazole. The best adsorbent properties correspond to the solid with highest porous volume. The samples obtained were characterized by $\mathrm{X}$-ray diffraction, ${ }^{29} \mathrm{Si}$ and ${ }^{27} \mathrm{Al}$ magic-angle spinning nuclear magnetic resonance, X-ray fluorescence and Fourier transform infrared spectroscopy. The Barrett-Joyner-Halenda (BJH) pore size distribution and the Brunauer-Emmet-Teller (BET) surface area values were obtained from $\mathrm{N}_{2}$ adsorption/desorption isotherms.
\end{abstract}

Keywords: nitrogen compound adsorption, rice hull ash, ZSM-5, faujasite Y

\section{Introduction}

The production of ultralow sulfur diesel (ULSD) is imperative worldwide due to current air pollution. Several environmental regulations have been established to achieve ultradeep hydrodesulfurization (HDS) ${ }^{1}$

Some basic nitrogen compounds exert an inhibiting effect when absorbed into the acid sites of HDS catalysts, while neutral compounds are prone to form gums that block the catalyst pores..$^{2-4}$ In this sense, nitrogenous compounds present in straight run gas oil (SRGO), coker gas oil (CGO) and light cycle oil (LCO), which are used as feedstocks for diesel fuel production, have been identified as strong inhibitors of HDS reactions due to catalyst poisoning. Therefore, elimination of these compounds is crucial to reaching the low sulfur levels that are required for fuels.

The nitrogenous compounds found in gas oil are generally divided into two groups: basic compounds, such

\footnotetext{
*e-mail: norma.sanchez@icat.unam.mx
}

$\dagger$ In memoriam. as aniline, pyridine, quinoline, acridine and their alkyl derivatives, and nonbasic compounds, such as pyrrole, indole, carbazole, and their alkyl derivatives. Due to the diversity of nitrogenous compounds, great interest has been focused on the study of different adsorbents for the selective removal of these compounds. ${ }^{5-14}$ The pretreatment of gas oil to remove nitrogenous compounds using silica, silica-alumina, activated carbon and zeolites has been proposed. ${ }^{14-16}$

Rice hull is an agricultural waste that is widely used to produce amorphous silica by physical combustion at controlled temperatures and has been used for synthesizing advanced materials such as $\mathrm{SiO}_{2}, \mathrm{SiC}, \mathrm{Si}_{3} \mathrm{~N}_{4}$, elemental $\mathrm{Si}$, $\mathrm{Mg}_{2} \mathrm{Si}$ and active carbon. ${ }^{17}$ On the other hand, different zeolites have been synthesized using the silica from rice hull, usually under hydrothermal conditions from solutions of sodium silicate. ${ }^{18,19}$

In this sense, extensive work has been carried out on the syntheses of ZSM-5 $5^{20-24}$ and Y zeolite ${ }^{25-30}$ with rice hull ash (RHA) as the source of silica. When rice hull is used as a silica and aluminum source, a highly siliceous ZSM-5 
(silicalite) is obtained. ${ }^{31-33}$ Additionally, a template-free synthesis of ZSM-5 has been reported. ${ }^{34-36}$ With an external aluminum source, such as aluminum sulfate ${ }^{37}$ or sodium aluminate, ${ }^{38-40}$ ZSM-5 samples with a micro-mesoporous nature have been obtained. However, a mesoporous Y zeolite has not been reported.

A novel technique for the preparation of mesoporous adsorbents using gels obtained from depolymerized silicates has been reported by our group..$^{41-46}$ This technique first involves the simultaneous depolymerization of a mixture of high-surface-area silica, such as rice hull ash (RHA), and of a crystalline zeolite, such as clinoptilolite or faujasite. This step is followed by partial reorganization induced by a structure-directing agent (SDA). Whit the simultaneous depolymerization of two silica sources, RHA and zeolite, silicate is enriched in silica, and the supplementary silica is not distributed at random; it is most likely attached to the dangling bonds of the attacked zeolite network and forms a porous material that is supported by the structured residue of the silica. Pacheco-Malagón et al..$^{43}$ have worked with ZSM-5 synthesized from residual rice hull.

In this contribution, emphasis is placed on the adsorption of large nitrogenous molecules that behave as poisons to HDS catalysts. The concept involves grafting porous siliceous materials onto a thermally stable network (zeolite) for the affordable synthesis of adsorbents capable of removing unwanted nitrogenous molecules.

\section{Experimental}

\section{Materials}

Three raw materials were used: rice hull ashes, natural clinoptilolite and acid faujasite CBV 720 by Zeolyst International (Kansas City, USA). Rice hull from Morelos, Mexico, were heated in air at $500{ }^{\circ} \mathrm{C}$ for $24 \mathrm{~h}$ to obtain RHA. ${ }^{45}$ Clinoptilolite from San Luis Potosi, Mexico, was milled, exchanged with a $0.1 \mathrm{M} \mathrm{NH}_{4} \mathrm{Cl}$ solution several times at room temperature and washed and purified several times by decantation. ${ }^{44}$ Tetrapropylammonium hydroxide (TPA) and tetramethylammonium hydroxide (TMA) were acquired from Sigma-Aldrich (Toluca, Mexico).

\section{Synthesis}

Two series of samples were prepared: $(i)$ from a mixture clinoptilolite and RHA that yielded the crystalline zeolite type ZSM-5 (ZSM samples) and (ii) using seeds of a well-crystallized faujasite $\mathrm{Y}$ and RHA that produced the semi-crystalline zeolite type faujasite Y (YRHA samples) (Table 1). The two-step preparation consisted of treating the starting solid mixture with $10 \mathrm{~mL}$ of anhydrous glycerol per $\mathrm{g}$ at $200{ }^{\circ} \mathrm{C}, 2 \mathrm{~h}$ for the ZSM samples and $3 \mathrm{~h}$ for the YRHA samples under continuous stirring. An amorphous organo-silicic gel was formed and was cooled to $50{ }^{\circ} \mathrm{C}$. The gel was hydrolyzed with TPA to obtain ZSM-5 (1.7 mL of a 1 M TPA solution per $\mathrm{g}$ and $5.1 \mathrm{~mL}$ of distilled water) or TMA for faujasite (0.06 $\mathrm{g}$ of TMA per $\mathrm{g}$ and $3.3 \mathrm{~mL}$ of distilled water). The gel was further aged in a cylindrical stainless steel reactor $(100 \mathrm{~mL}$ capacity $)$ to initiate a partial structural reorganization of the solid under autogenous pressure at $135{ }^{\circ} \mathrm{C}$ for $72 \mathrm{~h}$ for ZSM samples and $95{ }^{\circ} \mathrm{C}$ for $12 \mathrm{~h}$ for YRHA samples. Finally, the solid residue was washed by centrifugation three times at $5000 \mathrm{rpm}$, dried at $100{ }^{\circ} \mathrm{C}$ for $24 \mathrm{~h}$, and calcined at $500{ }^{\circ} \mathrm{C}$ for $24 \mathrm{~h}$.

Table 1. Clinoptilolite and faujasite content in the preparation of samples labeled ZSM (ZSM-5) and YRHA (faujasite Y) with rice hull ash (RHA)

\begin{tabular}{lcc}
\hline Sample & Clinoptilolite / wt.\% & RHA / wt. $\%$ \\
\hline ZSM-1 & 14 & 86 \\
ZSM-2 & 20 & 80 \\
ZSM-3 & 25 & 75 \\
ZSM-4 & 33 & 67 \\
\hline \multicolumn{3}{|c}{ Faujasite / wt. $\%$} \\
\hline YRHA-1 & 12.5 & 87.5 \\
YRHA-2 & 25 & 75 \\
YRHA-3 & 37.5 & 62.5 \\
\hline
\end{tabular}

Adsorption

Batch adsorption experiments were conducted for the powdered ZSM and YRHA samples in a beaker flask with a water-bath jacket. The temperature, pressure and stirring rate were set to $35^{\circ} \mathrm{C}, 0.078 \mathrm{MPa}$ and $330 \mathrm{rpm}$, respectively.

A model mixture was prepared by dissolving 53,27 and $27 \mathrm{mg}$ of quinolone, indole and carbazole, respectively, in $10 \mathrm{~mL}(8.03 \mathrm{~g})$ of a toluene/hexadecane mixture $(1 / 1 \mathrm{v} / \mathrm{v})$ to achieve final concentrations of each nitrogen compound of 41,23 and $16 \mathrm{mmol} \mathrm{L}^{-1}$. Next, $10 \mathrm{~mL}$ of this mixture was mixed with $1 \mathrm{~g}$ of sample and stirred at room temperature. Equilibrium data were obtained after $2 \mathrm{~h}$ of contact time, the solid was separated from the liquid by filtration. The content of nitrogenous compounds was determined by gas chromatography on a Bruker 450-GC model equipped with a pulsed photometric detector (PFPD) under $\mathrm{He}$ flow at $350{ }^{\circ} \mathrm{C}$ and a $50 \mathrm{~m} \times 0.32 \mathrm{~mm} \times 0.32 \mu \mathrm{m}$ fused silica capillary column coated with Bruker phase BR-5 (BR29730)d. The adsorption capacity was calculated from the difference between the initial and equilibrium 
concentrations of nitrogen compounds and corresponded to the analyzed pure nitrogen compounds.

\section{Characterization}

The ${ }^{29} \mathrm{Si}$ magic-angle spinning nuclear magnetic resonance (MAS NMR) spectra were obtained at $79.492 \mathrm{MHz}$ on a Bruker Advance 400; spinning zirconia rotors ( $4 \mathrm{~mm}$ internal diameter, at $7.5 \mathrm{kHz}, 90^{\circ}$ pulses in $20 \mathrm{~s}$ intervals) were used. The number of transients was $250 .{ }^{27} \mathrm{Al}$ MAS NMR spectra were also recorded. The NMR spectrum deconvolution was achieved using Origin 7 software. ${ }^{47}$

The X-ray diffraction (XRD) analyses of the samples were recorded with Siemens D-5000 equipment, which was fitted with a graphite secondary beam monochromator to filter $\mathrm{Cu} \mathrm{K} \alpha$ radiation. $\mathrm{X}$-ray diffractograms were recorded from 4 to $70^{\circ}$ with $2 \theta$ steps of $0.02^{\circ}$ and a $1.8 \mathrm{~s}$ counting time.

The chemical composition was determined by X-ray fluorescence (XRF) with XRF Siemens SRS300 fluorometer with a Rh tube and a $125 \mu \mathrm{m}$ Be window. The samples preparation technique was the fusion method, using metaborate and lithium tetraborate.

The textural properties of the evaluated solids were determined by nitrogen adsorption-desorption isotherms at $77 \mathrm{~K}$ with a Quantachrome Automated Gas Sorption System. The samples were previously outgassed under vacuum $\left(1.33 \times 10^{-10} \mathrm{MPa}\right)$ at $573 \mathrm{~K}(\mathrm{CDX}$ and $\mathrm{SG})$ and $473 \mathrm{~K}$ (VG-077) for $18 \mathrm{~h}$. The pore size distribution was calculated from the adsorption branch according to the Barrett-Joyner-Halenda (BJH) method, and the BrunauerEmmet-Teller (BET) model was used for calculating the total surface area of the solids.

Indole adsorption was monitored by Fourier transform infrared spectroscopy (FTIR) using a Nicolet 710 spectrometer. The spectra were obtained from self-supported sample pressed discs placed in a Pyrex cell equipped with $\mathrm{CaF}_{2}$ windows. Before the tests, the samples were outgassed at $673 \mathrm{~K}$ under vacuum. The active solid content in the discs was sufficient to provide IR spectra of good quality.

For FTIR study of nitrogen compound interactions, the indole was adsorbed at room temperature and progressively desorbed at different temperatures under vacuum. The temperature programming was as follows. First, the sample was heated at $400{ }^{\circ} \mathrm{C}$ in the vacuum system (activated sample). Afterwards, the temperature was lowered to room temperature, indole was introduced to the sample (pressed disc), and a second spectrum was recorded (Indole TA). To remove the indole, the temperature was increased to $300^{\circ} \mathrm{C}$ while spectra were recorded at different temperatures.

\section{Results and Discussion}

\section{Zeolite samples type MFI (ZSM-5)}

The following results were obtained by increasing the amount of clinoptilolite mixed with RHA in the starting material mixture and hydrolyzing with TPA. The main textural characteristics determined from the low temperature $\mathrm{N}_{2}$ adsorption-desorption isotherms are the pore volume $\left(\mathrm{cc} \mathrm{g}^{-1}\right)$ and surface area $\left(\mathrm{m}^{2} \mathrm{~g}^{-1}\right)$. For clinoptilolite, with relative contents between 14 (ZSM-1) and $33 \%$ (ZSM-4), the surface areas fluctuate from 330 to $227 \mathrm{~m}^{2} \mathrm{~g}^{-1}$ and the porous volume varies from 0.14 to $0.13 \mathrm{cc} \mathrm{g}^{-1}$, respectively (Table 2). The results of the chemical analysis show that the aluminum content increases according to the increase in the clinoptilolite content in the synthesis (Table 3). Impurities such as $\mathrm{K}_{2} \mathrm{O}, \mathrm{CaO}$ and $\mathrm{Fe}_{2} \mathrm{O}_{3}$ originate from the clinoptilolite and RHA.

Table 2. Properties of the samples derived from rice hull ash and clinoptilolite

\begin{tabular}{lccccc}
\hline Sample & $\mathrm{nSi} / \mathrm{nAl}$ & $\mathrm{BET}^{\mathrm{a}}$ surface area $/\left(\mathrm{m}^{2} \mathrm{~g}^{-1}\right)$ & Total pore volume / $\left(\mathrm{cc} \mathrm{g}^{-1}\right)$ & Average pore size / $\AA$ & XRD $^{\mathrm{b}}$ crystallinity / \% \\
\hline ZSM-1 & 39.69 & 330.3 & 0.1404 & 16.89 & 73.5 \\
ZSM-2 & 30.21 & 315.7 & 0.1312 & 16.84 & 71.7 \\
ZSM-3 & 25.42 & 299.6 & 0.127 & 16.89 & 68.5 \\
ZSM-4 & 19.69 & 227.2 & 0.133 & 17.54 & 67.5 \\
\hline
\end{tabular}

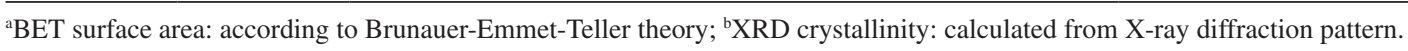

Table 3. Chemical analysis of the ZSM samples

\begin{tabular}{lccccccc}
\hline Sample & $\mathrm{SiO}_{2} /$ wt. $\%$ & $\mathrm{Al}_{2} \mathrm{O}_{3} / \mathrm{wt} . \%$ & $\mathrm{Na}_{2} \mathrm{O} / \mathrm{wt} . \%$ & $\mathrm{CaO} / \mathrm{wt} . \%$ & $\mathrm{~K}_{2} \mathrm{O} / \mathrm{wt} . \%$ & $\mathrm{MgO} / \mathrm{wt} . \% \mathrm{Fe}_{2} \mathrm{O}_{3} \mathrm{t} / \mathrm{wt} . \%$ \\
\hline ZSM-1 & 95.08 & 2.03 & 0.05 & 0.48 & 1.34 & 0.40 & 0.34 \\
ZSM-2 & 93.50 & 2.63 & 0.10 & 0.78 & 1.78 & 0.41 & 0.42 \\
ZSM-3 & 92.45 & 3.09 & 0.05 & 0.90 & 2.11 & 0.46 & 0.49 \\
ZSM-4 & 90.64 & 3.91 & 0.16 & 1.03 & 2.80 & 0.45 & 0.63 \\
\hline
\end{tabular}


Solids may be assumed to contain a homogeneous distribution of micropores (zeolitic pores) within a system of mesopores of identical chemical composition (Figure 1). One could imagine fragmented zeolite networks encased by a porous system of larger cavities. The choice of ZSM-5 was based on the toughness of its lattice and on previously published work. ${ }^{43}$

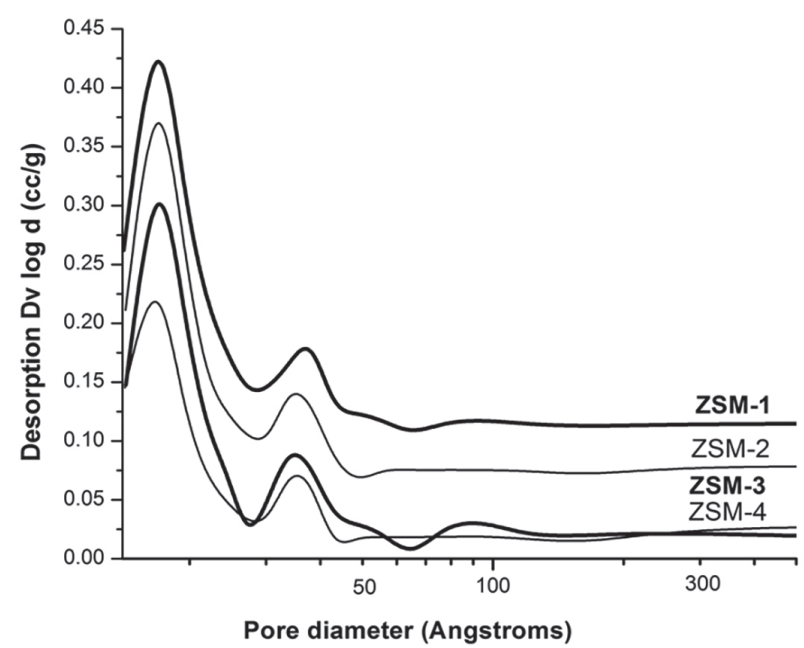

Figure 1. Mesopore diameter distribution of zeolite type ZSM-5.

The silicon and aluminum NMR spectra (Figures 2 and 3) reveal some fundamental characteristics of the process used to prepare these adsorbents. The ${ }^{29} \mathrm{Si}$ NMR spectra show three peaks upon deconvolution; the first and second peaks were assigned to $Q^{4}$ cluster resonances $(-113$ and $-115 \mathrm{ppm}$ ), and the third at $-104 \mathrm{ppm}$ corresponds to $\mathrm{Q}^{3}$ clusters. The $\mathrm{Q}^{4}$ resonance signal shows the fourfold coordination of silicon to oxygen with a varying $\mathrm{Si}-\mathrm{O}-\mathrm{Si}$ angle (Table 4). ${ }^{48}$ The small peak that emerged in the $\mathrm{Q}^{3}$ region increased with increasing clinoptilolite content, probably because of the contribution of aluminum. On the other hand, ${ }^{27} \mathrm{Al}$ NMR spectra show the presence of only one peak at $55.5 \mathrm{ppm}$, attributed to a tetrahedral structure, while no octahedral aluminum was detected (Figure 3).

After depolymerization, hydrolysis and aging, only a four-fold coordinated aluminum combined with silicon is observable, and the XRD pattern does not show diffraction

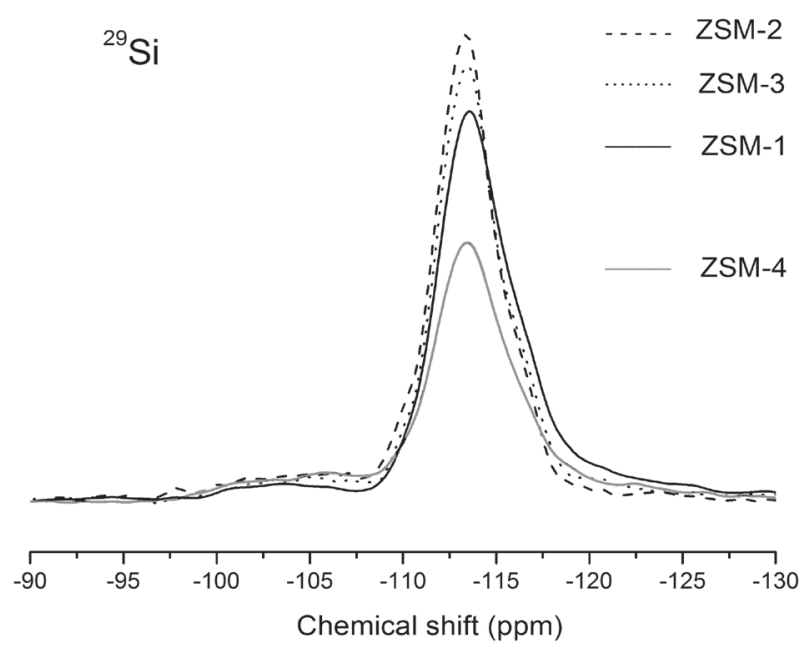

Figure 2. ${ }^{29} \mathrm{Si}$ NMR spectra of the ZSM samples.

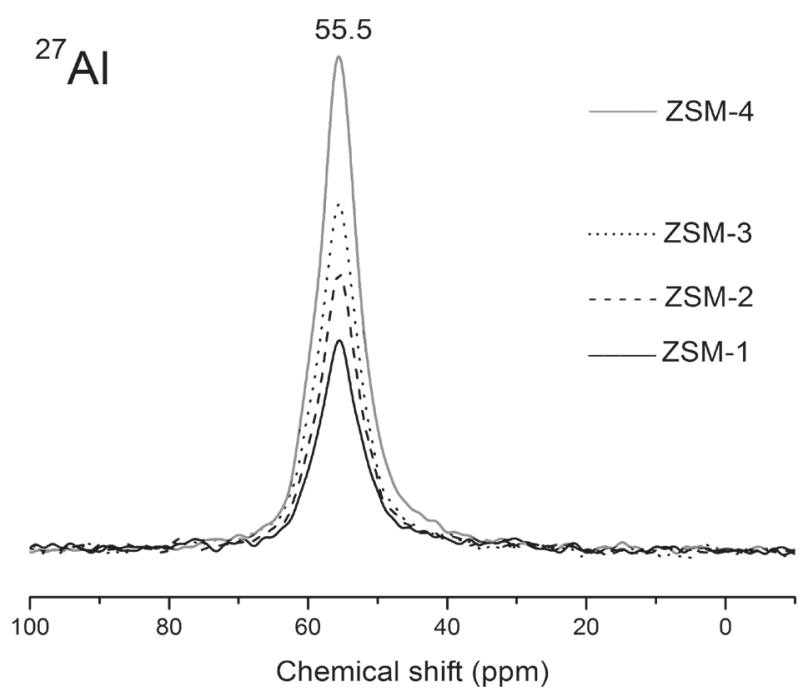

Figure 3. ${ }^{27} \mathrm{Al}$ NMR spectra of the ZSM samples.

lines other than those attributable to the MFI framework (Figure 4).

\section{Zeolite samples type faujasite}

The faujasite lattice is not as condensed as that of MFI. Three samples coded YRHA-1, YRHA-2 and YRHA-3 were prepared, their chemical analysis is reported on Table 5. Here the structural backbone is a faujasite

Table 4. ${ }^{29} \mathrm{Si}$ chemical shifts of the $\mathrm{Q}^{4}$ and $\mathrm{Q}^{3}$ clusters for the ZSM samples

\begin{tabular}{|c|c|c|c|c|c|c|}
\hline Sample & $\mathrm{Q}^{4}$ & Intensity $/ \%$ & $\mathrm{Q}^{4}$ & Intensity / \% & $\mathrm{Q}^{3}$ & Intensity $/ \%$ \\
\hline ZSM-1 & -115.6 & 31.0 & -113.3 & 64.3 & -104.3 & 4.7 \\
\hline ZSM-2 & -115.9 & 33.3 & -113.2 & 59.8 & -104.1 & 6.9 \\
\hline ZSM-3 & -115.3 & 35.8 & -113.1 & 53.3 & -104.5 & 10.9 \\
\hline ZSM-4 & -115.5 & 37.5 & -113.2 & 50.1 & -104.9 & 12.4 \\
\hline
\end{tabular}

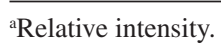




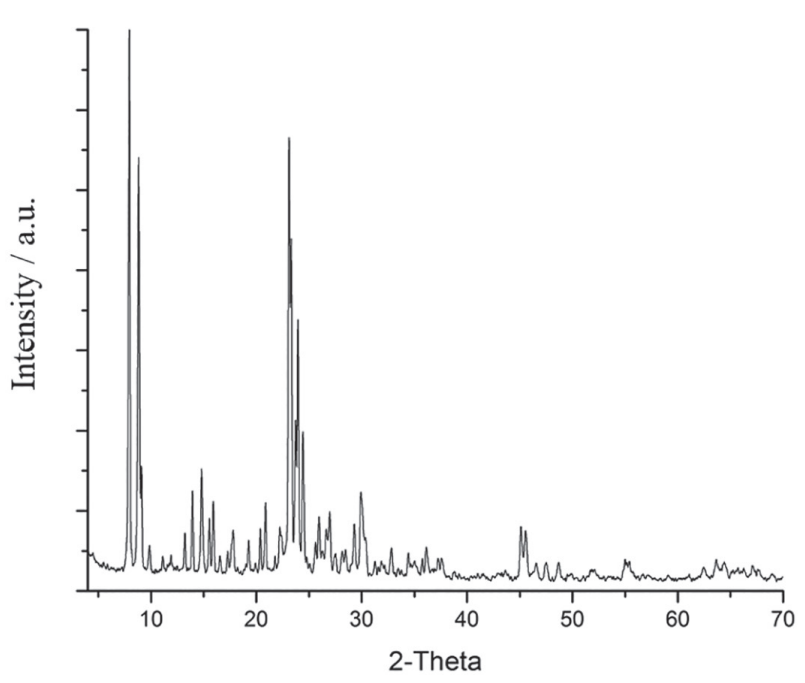

Figure 4. Diffraction pattern of the ZSM-1 sample.

synthesized from a relative amount of $\mathrm{NaY}$ between 12.5 and $37.5 \%$ (Table 1). The XRD pattern shows diffraction lines assigned to faujasite and halos due to amorphous silicon (Figure 5). Mesoporosity is characteristic in these samples (Figure 6).

Approximately $27 \%$ of the Y-type zeolite could be crystallized by this method, with a surface area between 169 and $258 \mathrm{~m}^{2} \mathrm{~g}^{-1}$ and a large pore size ranging from 73 to $95 \AA$ without an apparent correlation with the $\mathrm{Si} / \mathrm{Al}$ ratio. These results show that the residual silica greatly increased its textural properties, enabling the preparation of materials with large pore (samples YRHA-2 and YRHA-3) (Table 6).

Interactions between selected molecules and the adsorbents

It is necessary to determine whether selective adsorption occurs with respect to molecular shape or with respect to the adsorbent. For this purpose, a mixture of molecules was used for the ZSM and YRHA adsorption studies. A mixture

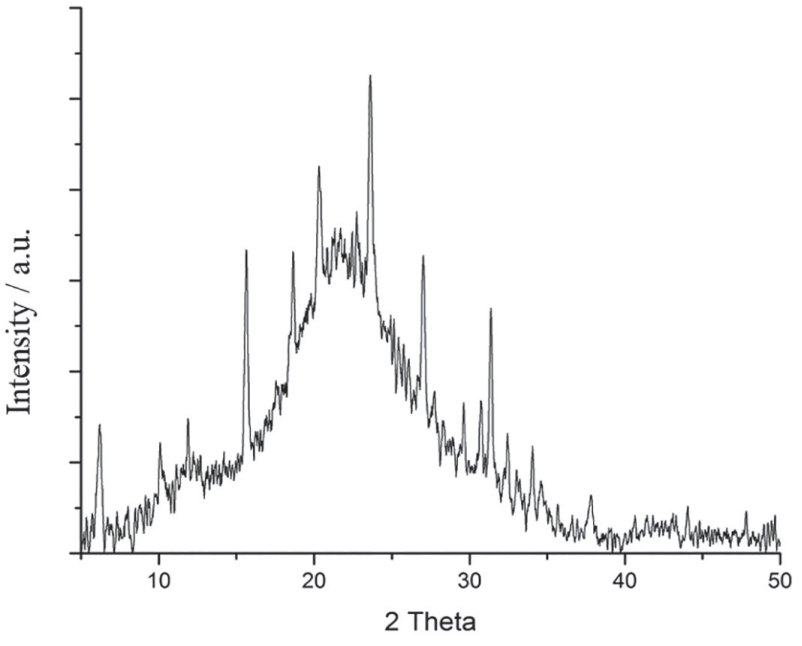

Figure 5. Diffraction pattern of the YRHA-2 sample.

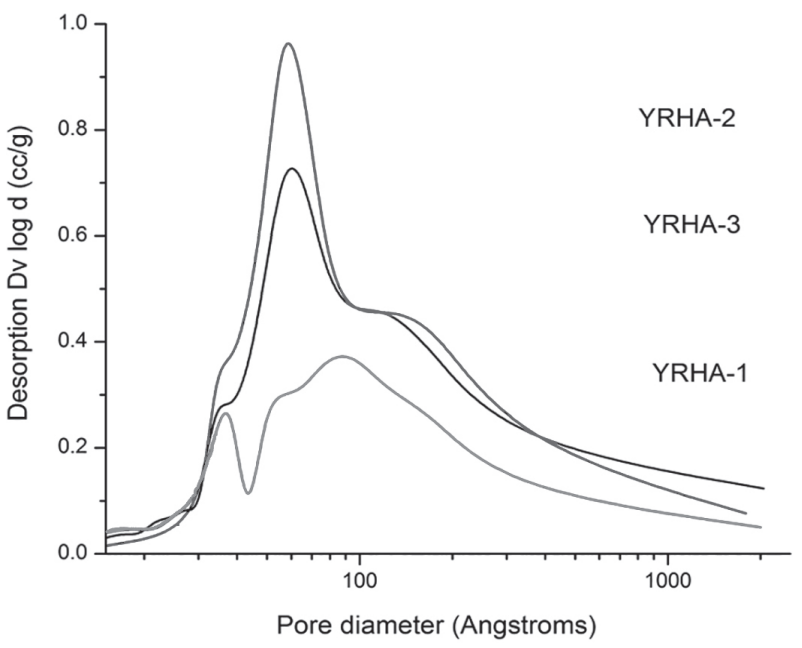

Figure 6. Mesopore diameter distribution of the YRHA samples.

of basic (quinoline) and neutral (indole and carbazole) nitrogen molecules was used. The chosen model molecules were heterocycles with 2 or 3 rings, the carbazole molecule is the largest (Table 7).

Table 5. Chemical analysis of the YRHA samples

\begin{tabular}{lccccccc}
\hline Sample & $\mathrm{SiO}_{2} / \%$ & $\mathrm{Al}_{2} \mathrm{O}_{3} / \%$ & $\mathrm{Na}_{2} \mathrm{O} / \%$ & $\mathrm{CaO} / \%$ & $\mathrm{~K}_{2} \mathrm{O} / \%$ & $\mathrm{MgO}_{2} / \%$ & $\mathrm{Fe}_{2} \mathrm{O}_{3} \mathrm{t} / \%$ \\
\hline YRHA-1 & 92.95 & 3.16 & 0.72 & 0.38 & 1.03 & 0.34 & 0.12 \\
YRHA-2 & 87.22 & 7.88 & 2.80 & 0.40 & 1.00 & 0.35 & 0.12 \\
YRHA-3 & 90.68 & 5.62 & 1.55 & 0.42 & 1.00 & 0.40 & 0.12 \\
\hline
\end{tabular}

Table 6. Properties of the samples derived from rice hull ash and faujasite

\begin{tabular}{lccccc}
\hline Sample & $\mathrm{nSi} / \mathrm{nAl}$ & $\mathrm{BET}^{\mathrm{a}}$ surface area $/\left(\mathrm{m}^{2} \mathrm{~g}^{-1}\right)$ & Total pore volume / $\left(\mathrm{cc} \mathrm{g}^{-1}\right)$ & Average pore size / $\AA$ & $\mathrm{XRD}^{\mathrm{b}}$ crystallinity / \% \\
\hline YRHA-1 & 24.99 & 169.5 & 0.31 & 73.2 & 25 \\
YRHA-2 & 9.75 & 255.7 & 0.59 & 83.5 & 29 \\
YRHA-3 & 13.71 & 257.7 & 0.61 & 94.9 & 24 \\
\hline
\end{tabular}

${ }^{a}$ BET surface area: according to Brunauer-Emmet-Teller theory; bRD crystallinity: calculated from X-ray diffraction pattern. 
Table 7. Characteristic properties of model molecules used

Quinoline

Analysis of the adsorbed molecules (Table 8) compared to the initial composition reveals some significant selectivity in favor of quinoline, followed by indole and then carbazole, indicating the relative acidic character of the solids despite not being in their acid form. Basic nitrogen compounds compete for the acid sites, while the adsorption of neutral nitrogen compounds occurs through H-bonding and $\pi$-electron interactions. ${ }^{49}$ Figure 7 shows the increase in quinoline adsorption in response to an increase in aluminum content, which is responsible for the acidity in the samples.

The adsorption of the nitrogenous model molecule compounds by the YRHA samples is greater than those reported for the ZSM samples. ZSM-3 and YRHA-1 with similar composition show that the adsorption capacity is most probably because of the larger pore volumes and pore sizes in the former. Among the adsorbents examined, the best appears to be YRHA-2, which is the one with the highest porous volume (Table 6).

Contact with the adsorbent removed between 0.15 and $0.44 \mathrm{mmol} \mathrm{g}^{-1}$ from $0.80 \mathrm{mmol} \mathrm{g}^{-1}$ added. It is evident that the density of the starting material plays an important role and should be investigated more thoroughly.

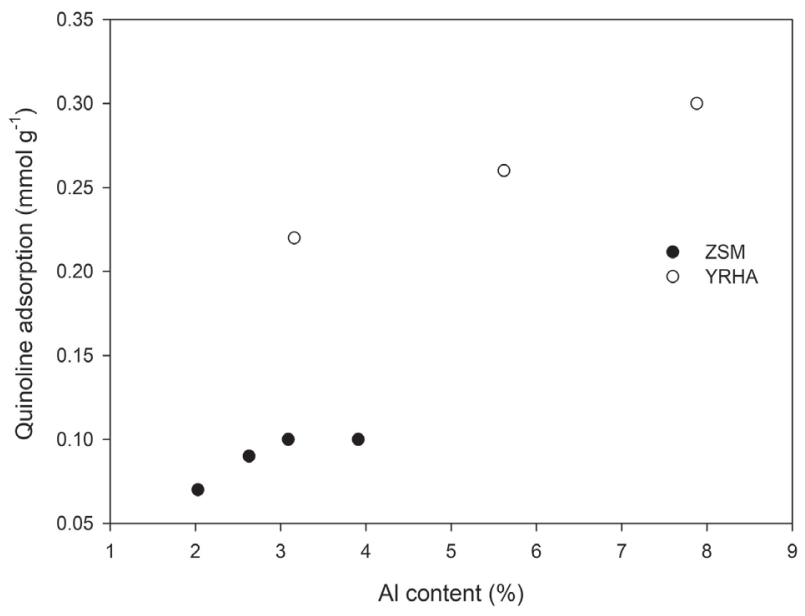

Figure 7. Quinoline adsorption on the ZSM and YRHA samples as a function of the Al content.

Infrared study

The trend revealed by the comparison of the two categories of adsorbents is encouraging. The surface chemical compositions of these adsorbents should only differ by the concentration of the chemical components. This aspect deserves more attention and will be studied using a molecular probe and infrared spectroscopy. Indole

Table 8. Adsorption capacity comparison between the adsorbents obtained

\begin{tabular}{lcccc}
\hline Sample & Quinoline $/\left(\mathrm{mmol} \mathrm{g}^{-1}\right)$ & Indole $/\left(\mathrm{mmol} \mathrm{g}^{-1}\right)$ & Carbazole $/\left(\mathrm{mmol} \mathrm{g}^{-1}\right)$ & Total $( \pm 0.003) /\left(\mathrm{mmol} \mathrm{g}^{-1}\right)$ \\
\hline Initial content & 0.41 & 0.23 & 0.16 & 0.80 \\
ZSM-1 & 0.07 & 0.04 & 0.04 & 0.15 \\
ZSM-2 & 0.09 & 0.04 & 0.05 & 0.18 \\
ZSM-3 & 0.10 & 0.05 & 0.02 & 0.17 \\
ZSM-4 & 0.10 & 0.05 & 0.05 & 0.20 \\
YRHA-1 & 0.22 & 0.04 & 0.03 & 0.28 \\
YRHA-2 & 0.30 & 0.08 & 0.06 & 0.44 \\
YRHA-3 & 0.26 & 0.07 & 0.05 & 0.38 \\
\hline
\end{tabular}


is an excellent IR probe because of the $\mathrm{N}-\mathrm{H}$ bond in the pentagonal ring. Moreover, indole is one of the molecules that poisons the catalysts.

The $\mathrm{N}-\mathrm{H}$ vibration bands of indole are extremely sensitive to interactions with $\mathrm{O}-\mathrm{H}$ or chemisorbed water, as has been shown by Carney et al..$^{50}$ They described the hydrogen-bonding topologies of indole-(water ${ }^{\mathrm{n}}$ clusters, where the $\mathrm{N}-\mathrm{H}$ stretch at $3524 \mathrm{~cm}^{-1}$ served as a reference for the indole-water cluster transitions. Thus, in spite of its complexity, it is possible to use the infrared spectrum of indole as a very rich source of information on its interactions with adsorbents.

The reactions of indole with these surfaces are different from what was expected. On silica gel, the reactivity mainly involves surface silanols. The intensity of the $\mathrm{O}-\mathrm{H}$ stretching decreases as the amount of desorbed indole increases. This observation implies a decrease in the number of hydrogen-bonded $\mathrm{O}-\mathrm{H}$ as well as a slight high frequency shift. On the sample, the dominant indole bands near 3600 and $3420 \mathrm{~cm}^{-1}$ exhibit different behaviors.

Fourier transform infrared spectroscopy (FTIR) of surfaces is a common tool utilized to study interactions between solids and molecules linked through the hydroxyl groups (i.e., indole). Considering the samples with higher adsorption capacities, Figures 8 and 9 display the FTIR spectra of the adsorbed species arising from the contact of YRHA-2 and ZSM-4 with indole. For ZSM-4, a saturation signal is observed in the region from 3800 to $3200 \mathrm{~cm}^{-1}$, indicating an excess of indole was adsorbed. In both series of spectra, the indole adsorption formed strong broad adsorption bands in the region from 3650 to $3250 \mathrm{~cm}^{-1}$. This band formed at the expense of the signal attributed to

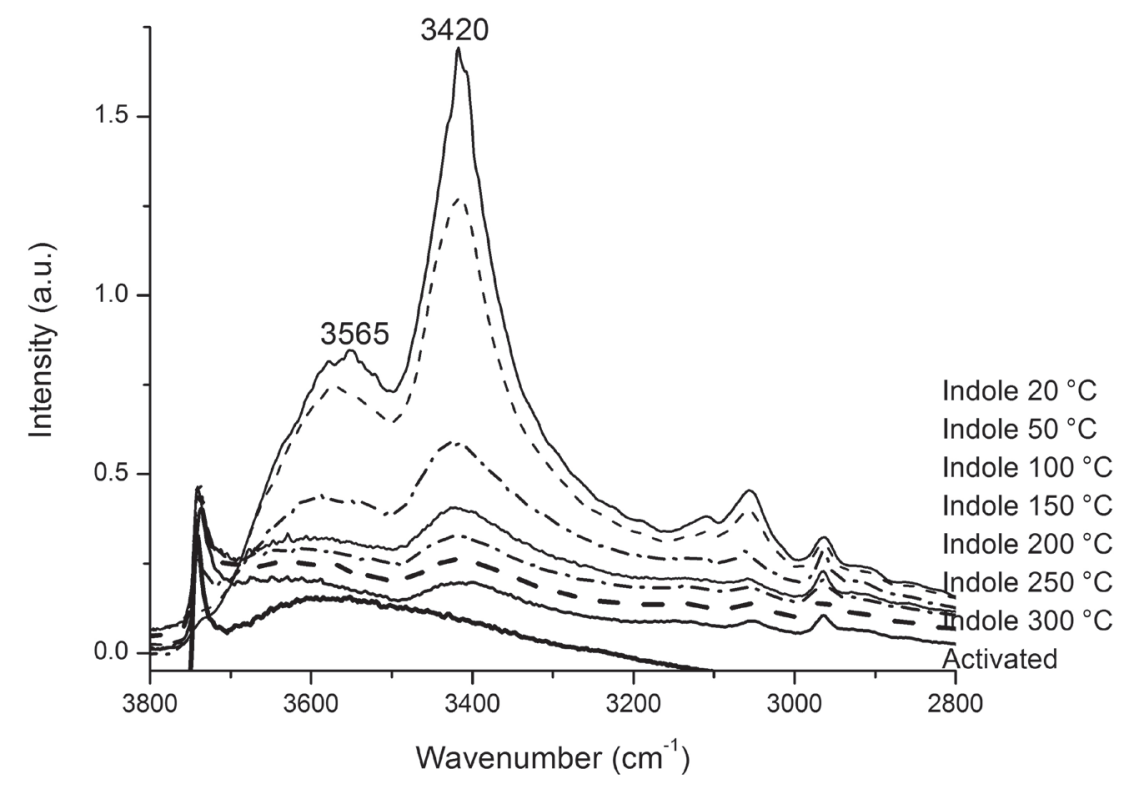

Figure 8. Infrared spectra of the adsorption-desorption behavior of indole on YRHA-2 at different temperatures.
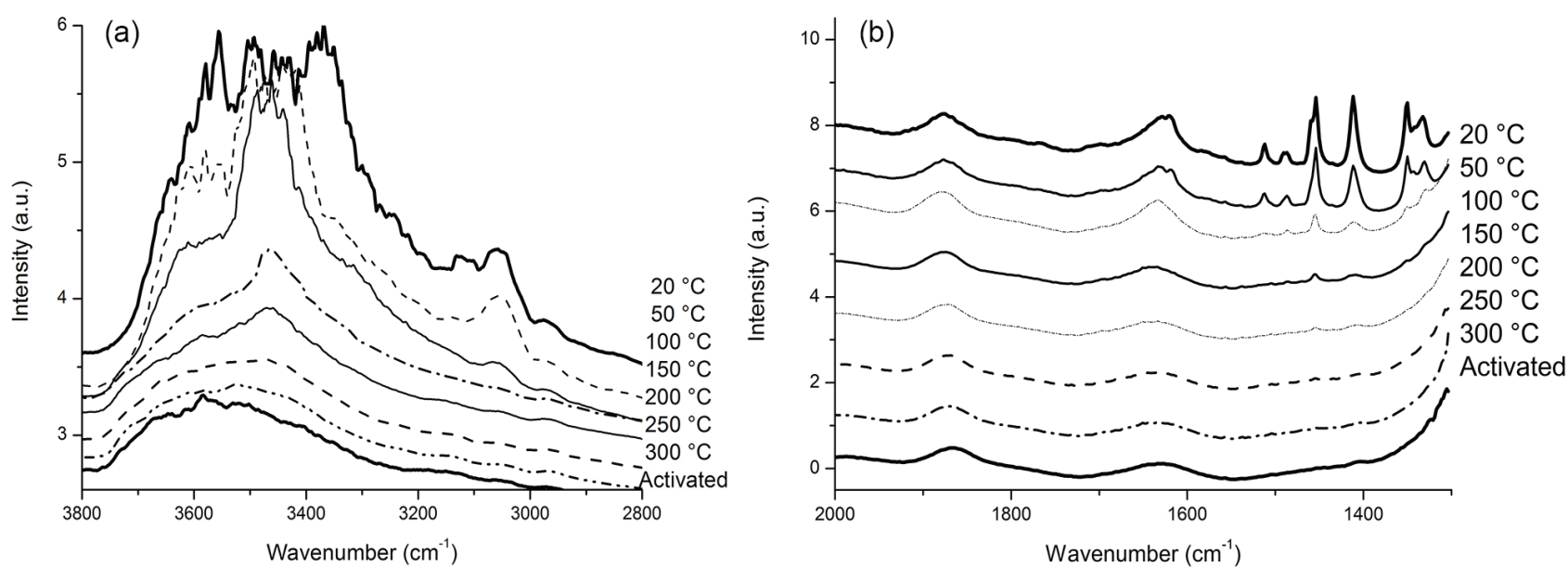

Figure 9. Infrared spectra of the adsorption-desorption of indole on ZSM-4 at different temperatures. The presence of indole is apparent in the ranges from 3800 to $3000 \mathrm{~cm}^{-1}$ (a) and 1600 to $1300 \mathrm{~cm}^{-1}$ (b). 
surface hydroxyls, which is typically observed in the region from 3800 to $3200 \mathrm{~cm}^{-1}$. This finding suggests that indole interacted with and perturbed the surface hydroxyl groups of YRHA-2 and ZSM-4 through hydrogen bonding. Though indole desorbed from ZSM-4 at $200{ }^{\circ} \mathrm{C}$, its presence on YRHA-2 remained even at $300{ }^{\circ} \mathrm{C}$; this finding suggests a stronger interaction with YRHA-2 and the formation of a surface complex. For ZSM-4, evidence of this complex is more clearly observed in the region from 1600 to $1300 \mathrm{~cm}^{-1}$, where a weakening of the indole signal is evident.

That strong interaction on YRHA-2 was expected due to the acidic character of the surface hydroxyl. To assist in explaining the observed behavior of ZSM-4, which contained a lower aluminum content than YRHA-2, it is necessary to note the importance of acidity in the adsorption capacity of solids with a donor-acceptor component in the interaction (i.e., hydrogen bonding). The strongest adsorption of organic compounds occurred when the dehydrated surface presented isolated hydroxyl groups.

These results demonstrate that indole interacts with both YRHA-2 and ZSM-4 through hydrogen bonding. Additionally, both materials exhibit a higher affinity for quinoline than for indole.

On YRHA-2 and ZSM-4, the affinity for carbazole is slightly higher than that for indole despite the steric effect and the pore volume of the materials.

\section{Conclusions}

Contact with mesoporous semi-crystalline adsorbents removed around $55 \%$ of the components in a model mixture. Although the adsorption of large nitrogenous molecules was satisfactory for a proof-of-concept, there remains room for improvement. More than $90 \%$ of $\mathrm{N}$-compounds should be eliminated by the adsorbent; however, the observed trends among the different solids are encouraging. It is evident that the density of the starting material plays important roles. The novel technique suggested here is promising and warrants further investigation.

\section{Acknowledgments}

In memory of a great researcher and teacher, but above all a great man and a great friend, José J. Fripiat.

We thank CONACYT for financial support (project 144141), Néstor R. Ortega from Instituto de Ciencias Aplicadas y Tecnologìa for contributing the experimental synthesis, Patricia Giron, from Instituto de Geología for contributing the X-ray fluorescence analysis and Adriana Tejeda, from Instituto de Investigaciones en Materiales for contributing the X-ray diffraction analysis, of Universidad Nacional Autónoma de México.

\section{Author Contributions}

José J. Fripiat was responsible for investigation (lead), formal analysis (lead) and writing original draft (lead); Norma A. Sánchez-Flores for investigation (lead), formal analysis (lead) and writing-review and editing (lead); Juan Navarrete-Bolaños for data curation (lead) and formal analysis (lead); Patrricia Pérez-Romo for investigation (lead), formal analysis (lead) and writing-review and editing (supporting); Graciela Pacheco-Malagón for investigation (supporting), formal analysis (lead), data curation (lead); Georgina Laredo for investigation (lead), formal analysis (lead), and writing-review and editing (supporting).

\section{References}

1. Srivastava, V. C.; RSC Adv. 2012, 2, 759.

2. Jeong, D. S.; Massoth, F. E.; Catal. Today 1997, 37, 267.

3. Ramachandran, R.; Massoth, F. E.; Chem. Eng. Commun. 1982, $18,239$.

4. Muegge, B.; Massoth, F. E.; Catalyst Deactivation; Bartholomew, C. H.; Butt, J. B., eds.; Elsevier: Amsterdam, 1991.

5. Kim, J. H.; Ma, X.; Zhou, A.; Song, C.; Catal. Today 2006, 111, 74.

6. Min, W.; Korean J. Chem. Eng. 2002, 19, 601.

7. Thomas, J. K.; Gunda, K.; Rehbein, P.; Ng, F. T. T.; Appl. Catal., B 2010, 94, 225.

8. Laredo, G. C.; Vega-Merino, P. M.; Trejo-Zárraga, F.; Castillo, J.; Fuel Process. Technol. 2013, 106, 21.

9. Almarri, M.; Ma, X.; Song, C.; Ind. Eng. Chem. Res.2009, 48, 951.

10. Rashidi, S.; Nikou, M. R. K.; Anvaripour, B.; Microporous Mesoporous Mater. 2015, 211, 134.

11. Mohammadian, M.; Ahmadi, M.; Khosravi-Nikou, M. R.; Pet. Sci. Technol. 2017, 35, 608.

12. Mohammadian, M.; Khosravi-Nikou, M. R.; Shariati, A.; Aghajani, M.; Clean Technol. Environ. Policy 2018, 20, 95.

13. Ahmadi, M.; Anvaripour, B.; Khosravi-Nikou, M. R.; Mohammadian, M.; J. Environ. Chem. Eng. 2017, 5, 849.

14. Hernandez-Maldonado, A. J.; Yang, R. T.; Angew. Chem. 2004, 43, 1004

15. Infantes-Molina, A.; Moreno-León, C.; Pawelec, B.; Fierro, J. L. G.; Rodríguez-Castellón, E.; Jiménez-López, A.; Appl. Catal., B 2012, 113-114, 87.

16. Sano, Y.; Choi, K. H.; Korai, Y.; Mochida, I.; Energy Fuels 2004, 18, 644.

17. Soltani, N.; Bahrami, A.; Pech-Canul, M. I.; González, L. A.; Chem. Eng. J. 2015, 264, 899. 
18. Hamdan, H.; Muhid, M. N. M.; Endud, S.; Listiorini, E.; Ramli, Z.; J. Non-Cryst. Solids 1997, 211, 126.

19. Sun, L.; Gong, K.; Ind. Eng. Chem. Res. 2001, 40, 5861.

20. Rawtani, A. V.; Rao, M. S.; Gokhale, K. V. G. K.; Ind. Eng. Chem. Res. 1989, 28, 1411.

21. Chareonpanich, M.; Namto, T.; Kongkachuichay, P.; Limtrakul, J.; Fuel Process. Technol. 2004, 85, 1623.

22. Ali, I. O.; Hassan, A. M.; Shaaban, S. M.; Soliman, K. S.; Sep. Purif. Technol. 2011, 83, 38.

23. Prasetyoko, D.; Ayunanda, N.; Fansuri, H.; Hartanto, D.; Ramli, Z.; ITB J. Sci. 2012, 44A, 250.

24. Kordatos, K.; Ntziouni, A.; Iliadis, L.; Kasselouri-Rigopoulou, V.; J. Mater. Cycles Waste Manage. 2013, 15, 571.

25. Wittayakun, J.; Khemthong, P.; Prayoonpokarach, S.; Korean J. Chem. Eng. 2008, 25, 861.

26. Yusof, A. M.; Nizam, N. A.; Rashid, N. A. A.; J. Porous Mater. 2010, 17, 39.

27. Tan, W. C.; Yap, S. Y.; Matsumoto, A.; Othman, R.; Yeoh, F. Y.; Adsorption 2011, 17, 863.

28. Saceda, J.-J. F.; de Leon, R. L.; Rintramee, K.; Prayoonpokarach, S.; Wittayakun, J.; Quim. Nova 2011, 34, 1394.

29. Rahman, M. M.; Awang, M. B.; Yusof, A. M.; Adv. Mater. Res. 2012, 445, 821.

30. Mohamed, R. M.; Mkhalid, I. A.; Barakat, M. A.; Arabian J. Chem. 2015, 8, 48.

31. Wang, H. P.; Lin, K. S.; Huang, Y. J.; Li, M. C.; Tsaur, L. K.; J. Hazard. Mater. 1998, 58, 147.

32. Kordatos, K.; Gavela, S.; Ntziouni, A.; Pistiolas, K. N.; Kyritsi, A.; Kasselouri-Rigopoulou, V.; Microporous Mesoporous Mater. 2008, 115, 189.

33. Katsuki, H.; Furuta, S.; Watari, T.; Komarneni, S.; Microporous Mesoporous Mater. 2005, 86, 145.

34. Fernandes, A. A.; Frajndlich, E. U.; Riella, H. G.; Mater. Sci. Forum 2005, 499, 676.

35. Vempati, R. K.; Borade, R.; Hegde, R. S.; Komarneni, S.; Microporous Mesoporous Mater. 2006, 93, 134.

36. Jesudoss, S. K.; Vijaya, J. J.; Kaviyarasu, K.; Kennedy, L. J.; Ramalingam, R. J.; Al-Lohedam, H.; RSC Adv. 2018, 8, 481.
37. Mohamed, M. M.; Zidan, F. I.; Thabet, M.; Microporous Mesoporous Mater. 2008, 108, 193.

38. Panpa, W.; Jinawath, S.; Appl. Catal., B 2009, 90, 389.

39. Naskar, M. K.; Kundu, D.; Chatterjee, M.; J. Am. Ceram. Soc. 2012, 95, 925.

40. Dey, K. P.; Ghosh, S.; Naskar, M. K.; Ceram. Int. 2013, 39 , 2153.

41. Sánchez-Flores, N. A.; Pacheco-Malagón, G.; Perez-Romo, P.; Armendáriz, H.; Guzmán-Castillo, M. L.; Saniger, J. M.; Fripiat, J. J.; J. Colloid Interface Sci. 2008, 323, 359.

42. Pérez-Romo, P.; Armendáriz-Herrera, H.; Valente, J. S.; Guzmán-Castillo, M. L.; Hernández-Beltrán, F.; Fripiat, J. J.; Microporous Mesoporous Mater. 2010, 132, 363.

43. Pacheco-Malagón, G.; Sanchez-Flores, N. A.; Saniger-Blesa, J.; Baños, L.; Pérez-Romo, P.; Valente, J. S.; Guzmán-Castillo, M. L.; Hernández-Beltrán, F.; Fripiat, J. J.; Microporous Mesoporous Mater. 2007, 100, 70.

44. Pacheco-Malagón, G.; Pérez-Romo, P.; Sánchez-Flores, N. A.; Guzmán-Castillo, M. L.; López-Franco, C.; Saniger, J. M.; Hernández-Beltrán, F.; Fripiat, J. J.; Inorg. Chem. 2006, 45, 3408.

45. Sánchez-Flores, N. A.; Pacheco-Malagón, G.; Perez-Romo, P.; Armendáriz, H.; Guzmán-Castillo, M. L.; Saniger, J. M.; Fripiat, J. J.; J. Chem.Technol. Biot. 2007, 82, 614.

46. Pacheco-Malagón, G.; Pérez-Romo, P.; Sánchez-Flores, N. A.; Guzmán-Castillo, M. L.; López, C.; Saniger, J. M.; Hernández-Beltrán, F.; Fripiat, J. J.; Inorg. Chem. 2005, 44, 8486.

47. Origin, version 7.5; Origin Lab Corporation, USA, 2003.

48. Engelhardt, G.; Michel, D.; High-Resolution Solid State NMR of Silicates and Zeolites; John Wiley and Sons: New York, 1987.

49. Laredo, G. C.; Vega-Merino, P. M.; Pérez-Romo, P.; Navarrete-Bolaños, J.; Trejo-Zárraga, F.; Pet. Sci. Technol. 2017, 35, 392.

50. Carney, J. R.; Hagemeister, F. C.; Zwier, T. S.; J. Chem. Phys. 1998, 108, 3379.

Submitted: February 24, 2020

Published online: August 18, 2020 